\title{
Endoscopy Under Anesthesia
}

National Cancer Institute

\section{Source}

National Cancer Institute. Endoscopy Under Anesthesia. NCI Thesaurus. Code C150657.

Any endoscopic procedure done while the patient is sedated. 